\title{
Effect of pulmonary rehabilitation on exhaled nitric oxide in patients with chronic obstructive pulmonary disease
}

\author{
E Clini, L Bianchi, K Foglio, R Porta, M Vitacca, N Ambrosino
}

\begin{abstract}
Background-In patients with mild to moderate chronic obstructive pulmonary disease (COPD) the exercise induced increase in exhaled nitric oxide (eNO) parallels that observed in normal untrained subjects. There is no information on the effects of the level of exercise tolerance on eNO in these patients. The aim of this study was to evaluate the effect of a pulmonary rehabilitation programme including exercise training on eNO in patients with COPD.
\end{abstract}

Methods-In 14 consecutive male patients with stable COPD of mean (SD) age 64 (9) years and forced expiratory volume in one second $\left(F E V_{1}\right) 55$ (14)\% predicted, fractional eNO concentration (FeNO), peak work rate (Wpeak) and oxygen uptake ( $\dot{\mathrm{O}}_{2}$ peak) were assessed at baseline $(\mathbf{T}-1)$, at the end of a 1 month run in period (T0), and after an 8 week outpatient multidisciplinary pulmonary rehabilitation programme (T1) including cycloergometer training.

Results-Feno did not significantly differ at T-1 and T0 (mean (SE) 4.3 (0.6) and 4.4 (0.6) ppb, respectively), whereas it rose significantly at $\mathrm{T} 1$ to $6.4 \quad(0.7) \mathrm{ppb}$ $(\mathrm{p}<0.02)$. Compared with T0, both Wpeak and $\dot{\mathrm{V}}_{2}$ were significantly $(p<0.05)$ increased at T1 (mean (SE) Wpeak from 89 (5.6) $\mathrm{W}$ to 109 (6.9) W); $\dot{V}_{2}$ peak from 1.27 $(0.1) 1 / \mathrm{min}$ to $1.48(0.1) 1 / \mathrm{min})$. A significant correlation was found between baseline $\mathrm{FEV}_{1}$ and the change in Feno following the rehabilitation programme $(r=-0.71$; $p<0.05)$ and between changes in Feno and Wpeak from T0 to $\mathrm{T} 1(r=0.60 ; \mathrm{p}<0.05)$. Conclusions-Pulmonary rehabilitation in patients with mild to moderate COPD is associated with an increase in exhaled nitric oxide.

(Thorax 2001;56:519-523)

Keywords: chronic obstructive pulmonary disease; exercise training; exhaled nitric oxide

Synthesis of nitric oxide (NO) in the respiratory system of animals and humans has been evaluated in vivo by measuring the concentration of $\mathrm{NO}$ in the exhaled air (eNO). ${ }^{1}$ Exhaled nitric oxide is increased in inflammatory lung disease ${ }^{23}$ and reduced in primary pulmonary hypertension. ${ }^{4-7}$ Exhaled nitric oxide is also reduced $^{6}$ in patients with severe chronic obstructive pulmonary disease (COPD) ${ }^{8}$ and it has been suggested as a marker of severity of disease..$^{10}$

Impaired exercise tolerance is a common finding in patients with COPD. This feature is not a simple consequence of the loss of pulmonary function. Reduced exercise capacity shows only a weak relation to lung function impairment. Other factors such as peripheral and respiratory muscle weakness and deconditioning are now recognised as important contributors to reduced exercise tolerance. ${ }^{11}$ It has been shown that, in these patients, pulmonary rehabilitation programmes are likely to improve exercise capacity and health related quality of life (HRQL) if they also include exercise training. ${ }^{12}$

In healthy subjects eNO has been shown to increase markedly during exercise. ${ }^{13}$ Furthermore, in trained but not in sedentary healthy subjects it has been reported to be directly correlated with oxygen uptake $\left(\dot{\mathrm{V}}_{2}\right)$ during steady state exercise, suggesting that physical conditioning may induce an increase in eNO output during exercise. ${ }^{14}$ In patients with mild to moderate COPD an increase in eNO during exercise has been reported to parallel that observed in normal untrained subjects, ${ }^{15}$ but there is no information on the effects of the level of exercise tolerance on eNO in these patients with COPD. An effect on eNO (if any) might explain the observed benefits of pulmonary rehabilitation programmes including exercise training. ${ }^{16}$ The aim of this study was therefore to assess the effects on eNO of an 8 week outpatient rehabilitation programme including exercise training in patients with mild to moderate COPD.

\section{Methods}

Patients gave their informed consent to participate in the study which was approved by the ethical committee of Salvatore Maugeri Foundation IRCCS and was conducted according to the Declaration of Helsinki.

\section{PATIENTS}

Fourteen consecutive sedentary men with stable COPD referred from 1 January to 30 June 1999 for a multidisciplinary outpatient pulmonary rehabilitation programme described elsewhere ${ }^{17}$ were enrolled in the study. Diagnosis was made according to the American Thoracic Society (ATS) guidelines. ${ }^{8}$ All the patients were well known in our institution to which they were referred by attending physicians for periodic medical visits, lung function 
assessment, and eventually a pulmonary rehabilitation programme. All patients were exsmokers and none had any history of atopy. At the time of the study all of them were clinically and physiologically stable. Patients who had been hospitalised or had suffered from an exacerbation of their disease within the preceding 4 weeks were excluded, as were patients with other organ failure, cancer, an unwillingness to cooperate, or inability to perform an exercise test. All the patients were receiving their regular treatment with inhaled anticholinergic drugs and rescue short term $\beta_{2}$ agonists but not systemic or inhaled steroids. None of the patients was receiving long term oxygen. No change in medical treatment was made the week before and during the study period. Fifteen healthy sedentary subjects served as controls for eNO assessment.

\section{STUDY DESIGN}

The study was prospective and controlled, the patients serving as their own controls. Lung function was assessed only at baseline $(T-1)$ as there is no evidence that pulmonary rehabilitation programmes affect it. ${ }^{12}$ Measurements of eNO and cycloergometry were performed at $\mathrm{T}-1$, at the end of a 1 month run in period (T0), and after the completion of an 8 week outpatient pulmonary rehabilitation programme (T1). To further assess the clinical effects of the pulmonary rehabilitation programme, the 6 minute walking distance test (6MWD) and HRQL were measured before (T0) and after it (T1).

\section{MEASUREMENTS}

Lung function

Static and dynamic lung volumes were measured by constant volume body plethysmography (Medical Graphic Corp, St Paul, MN, USA) with the patient in the seated position according to the standard procedure. The predicted values according to Quanjer ${ }^{18}$ were used.

\section{Exercise test}

A symptom limited incremental exercise test was performed on an electrically braked cycloergometer (Ergometrics 800S, Sensormedics, Yorba Linda, CA, USA) using the standard 1 minute incremental cycle exercise protocol. Functional and metabolic data were determined at rest and during exercise by means of a computerised system (2900Z, Sensormedics, Yorba Linda, CA, USA). Breathing pattern and minute ventilation $(\dot{\mathrm{V}} \mathrm{E}), \dot{\mathrm{V}}_{2}$, and carbon dioxide production $\left(\dot{\mathrm{V}} \mathrm{CO}_{2}\right)$ were continuously monitored as mean values of $20 \mathrm{sec}-$ ond intervals. Electrocardiographic activity was monitored continuously and systemic arterial blood pressure was recorded every minute using a sphygmomanometer. After stabilisation and a 2 minute period of unloaded pedalling at 60 cycles per minute the load was increased by 10 Watts (W) each minute. The patients were strongly encouraged to cycle to the point of intolerable breathlessness, discomfort, or exhaustion until the maximal heart rate was achieved or an abnormal electrocardiogram noted (symptom limited exercise test). Noninvasive estimation of the $\dot{\mathrm{V}}_{2}$ lactate threshold (AT) was calculated by the V-slope method. ${ }^{19}$ At rest and at $10 \mathrm{~W}$ intervals, patients were asked their perceived breathlessness and leg fatigue by pointing to a number or phrase on a 10 point modified Borg scale set in large type on a sheet in front of them. ${ }^{20}$

The $6 \mathrm{MWD}^{21}$ and the HRQL using the St George's Respiratory Questionnaire (SGRQ) ${ }^{22}$ were also assessed before and after the pulmonary rehabilitation programme ( $\mathrm{T} 0$ and $\mathrm{T} 1$ )

\section{Exhaled NO}

Patients were asked to abstain from food for at least 4 hours and from alcohol for at least 24 hours before the experiment. Exhaled NO measurement was performed online at rest by means of a chemiluminescence analyser (LR 2000 series, Logan Research, Rochester, UK) as previously described ${ }^{6}$ with a constant expiratory flow of more than $200 \mathrm{ml} / \mathrm{s}$ (range $250-300 \mathrm{ml} / \mathrm{s}$ ). The analyser was calibrated daily using a certified NO mixture (108 ppb) in nitrogen (Messer Italia SpA, Collegno, Italy). The NO concentration in the ambient air was measured immediately before the study and, if it was higher than $30 \mathrm{ppb}$, patient testing was delayed. During the measurement of NO patients exhaled at constant expiratory pressure and flow up to a steady plateau by using a visual display of expiratory flow measured by the pressure and volume sensor in the analyser. The mean value of three reproducible readings (less than 5\% intrapatient variability) of eNO plateau (FeNo) was taken. ${ }^{23}$ The modalities of assessment were recorded and maintained constant for each patient for the different periods of evaluation (see study design).

Measurements were performed in the morning on two consecutive days: lung function, eNO and 6MWD in this order on day 1; exercise test and SGRQ on the next morning. The data were collected by physicians and technicians not involved in the study who were blind to eNO measurements.

\section{Pulmonary rehabilitation programme}

The pulmonary rehabilitation programme was a multidisciplinary programme ${ }^{17}$ consisting of three 3 hour sessions per week for 8-10 weeks including (1) supervised incremental exercise until patients achieved 30 minutes of continuous cycling at $50-70 \%$ of the maximal load achieved on an incremental cycloergometer exercise test carried out at admission ${ }^{24}$; (2) abdominal, upper and lower limb muscle activities lifting progressively increasing light weights (300-500 g), shoulder and full arm circling $^{25}$; (3) patient and family specific education - for example, whether patients were focused on abstaining from smoking, environmental control, and on the management plans.

\section{STATISTICAL ANALYSIS}

All data are shown as mean (SD) or (SE) as specified. The time course of the results in patients was analysed using a one way ANOVA for repeated measures. A post hoc test with Bonferroni correction was then used when 
Table 1 Mean (SD) demographic, anthropometric, and lung function data

\begin{tabular}{|c|c|c|}
\hline Age (years) & 65 & (6) \\
\hline Weight $(\mathrm{kg})$ & 77 & (5) \\
\hline Height $(\mathrm{cm})$ & 168 & (5) \\
\hline $\operatorname{BSA}\left(\mathrm{m}^{2}\right)$ & 1.9 & $(0.1)$ \\
\hline BMI $\left(\mathrm{kg} / \mathrm{m}^{2}\right)$ & 27 & (2) \\
\hline $\mathrm{FEV}_{1}(\mathrm{l})$ & 1.6 & $(0.4)$ \\
\hline $\mathrm{FEV}_{1}(\%$ pred $)$ & 55 & (14) \\
\hline TLC (\% pred) & 106 & (11) \\
\hline RV (\% pred) & 131 & (30) \\
\hline FEV/FVC (\%) & 54 & (12) \\
\hline
\end{tabular}

$\mathrm{BSA}=$ body surface area BMI = body mass index; $\mathrm{FEV}_{1}=$ forced expiratory volume in one second; FVC = forced vital capacity; TLC = total lung capacity; RV = residual volume.

requested. Within subject reproducibility of NO measurements was analysed by ANOVA for repeated measures with Huynh-Feldt correction. The Wilcoxon matched paired test was used to test differences in non-parametric measures. Spearman analysis was then used to evaluate the linear correlation coefficient between FeNO and functional parameters. A p value of $<0.05$ was considered to be statistically significant.

\section{Results}

Of 27 patients with COPD admitted to the pulmonary rehabilitation programme, 13 were excluded due to smoking $(n=2)$, use of inhaled steroids $(n=5)$, or severe associated diseases $(n=6)$. Fourteen patients fulfilled the inclusion criteria and entered the study. Their demographic, anthropometric, and functional characteristics are shown in table 1 . According to the ATS standards ${ }^{8} 10$ of the patients were in COPD stage I and four in stage II.

Exercise tolerance

The time course of exercise performance as assessed by cycloergometry and 6MWD is shown in table 2. As expected, no differences were found in peak work rate, cardiopulmonary parameters, and sensations of dyspnoea and leg fatigue at the end of the run in period (T0). At the end of the pulmonary rehabilitation programme (T1) a significant improvement in exercise tolerance as assessed by peak cycloergometry work rate and 6MWD was observed. Sensations of dyspnoea and leg fatigue at the same work load were also significantly reduced.

Table 2 Mean (SE) effects of rehabilitation on exercise response

\begin{tabular}{|c|c|c|c|c|}
\hline \multirow{2}{*}{$\frac{\text { Variables }}{\text { Wpeak (W) }}$} & $T-1$ & TO & \multicolumn{2}{|l|}{$T 1$} \\
\hline & $87.8(5.7)$ & $89.3(5.6)$ & 109 & $(6.9) \dagger$ \\
\hline Peak $\dot{V}_{\mathrm{CO}_{2}}(1 / \mathrm{min})$ & $1.27(0.1)$ & $1.26(0.1)$ & 1.53 & $(0.1) \dagger$ \\
\hline Peak $\dot{V}_{\mathrm{O}_{2}}(1 / \mathrm{min})$ & $1.25(0.1)$ & $1.27(0.1)$ & 1.48 & $(0.1) \dagger$ \\
\hline Peak $\dot{\text { V̇o }} / / \mathrm{kg}(\mathrm{ml} / \mathrm{min} / \mathrm{kg})$ & $16.1(0.9)$ & $16.4 \quad(0.8)$ & 19.2 & $(1.0) \dagger$ \\
\hline Rest $\dot{\mathrm{V}} \mathrm{E}(1 / \mathrm{min})$ & $11.8(0.7)$ & $11.8 \quad(0.7)$ & 10.5 & $(0.8)$ \\
\hline Peak $\dot{V}_{E}(1 / \mathrm{min})$ & $41.6 \quad(2.7)$ & $41.5 \quad(2.6)$ & 46.4 & $(2.6)$ \\
\hline Peak D (score) & $6.4 \quad(1.2)$ & $6.0(1.4)$ & 5.8 & $(1.4)$ \\
\hline Peak F (score) & 6.7 (1.1) & $6.4(1.3)$ & 6.2 & (1.3) \\
\hline AT $(\mathrm{ml} / \mathrm{min} / \mathrm{kg})$ & $11.1(1.5)$ & $11.3(1.1)$ & 12.3 & $(0.7)$ \\
\hline Iso $\mathrm{VO}_{2} \dot{\mathrm{V}} \mathrm{E}(1 / \mathrm{min})$ & & $40.5 \quad(1.7)$ & 39.2 & $(1.8)$ \\
\hline IsoW VE $(1 / \mathrm{min})$ & & $40.1 \quad(2.2)$ & 39.7 & $(2.6)$ \\
\hline IsoW $\mathrm{V}_{2}(\mathrm{l} / \mathrm{min})$ & & $1.22(0.1)$ & 1.24 & $(0.1)$ \\
\hline IsoW $\dot{V}_{2} / \mathrm{kg}(\mathrm{ml} / \mathrm{min} / \mathrm{kg})$ & & $15.8 \quad(0.8)$ & 16.0 & $(0.8)$ \\
\hline IsoW D (score) & & $6.5(1.4)$ & 4.4 & $(1.0) \dagger$ \\
\hline IsoW F (score) & & $6.5 \quad(1.1)$ & 4.2 & $(0.9) \dagger$ \\
\hline 6MWD (m) & & $483 \quad(13.6)$ & 512 & $(17.9) \ddagger$ \\
\hline
\end{tabular}

$\nmid$ Post hoc for $\mathrm{p}<0.01$ (T1 $v$ T0 and $\mathrm{T}-1)$; $\neq$ post hoc for $\mathrm{p}<0.01$ (T1 $v$ T0).

$\dot{\mathrm{V}}_{2}=$ carbon dioxide consumption $; \dot{\mathrm{VO}}_{2}=$ oxygen uptake; $\dot{\mathrm{VE}}=$ minute ventilation; $\mathrm{AT}=$ aerobic threshold; $6 \mathrm{MWD}=6$ minutes walking capacity; $\mathrm{D}=$ dyspnoea on Borg scale $; \mathrm{F}=$ leg fatigue on Borg scale.
Table 3 Effects of rehabilitation on quality of life (SGRQ)

\begin{tabular}{lll}
\hline Variables & To & T1 \\
\hline Total, score & $35(13-60)$ & $27(10-59) \dagger$ \\
Symptoms, score & $36(16-88)$ & $35(16-79) \ddagger$ \\
Activity, score & $38(14-59)$ & $47(17-60)$ \\
Impact, score & $11(1-42)$ & $10(0-56)$ \\
\hline
\end{tabular}

Data are as median (range)

$\mathrm{tp}<0.005$ (T1 v T0); 邦<0.02 (T1 v T0).

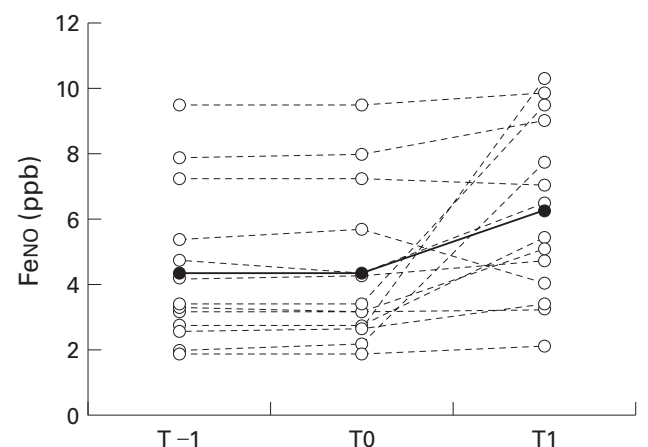

Figure 1 Individual (dotted line) and mean values (continuous line) of FeNO measured 1 month $(T-1)$, immediately before (TO) and after (T1) the pulmonary rehabilitation programme. Post hoc for $p<0.01 \mathrm{~T} 1 v \mathrm{TO}$ and $T-1$.

Quality of life

The time course of HRQL as assessed by SGRQ (total and component scores) is shown in table 3. The total SGRQ score improved after the pulmonary rehabilitation programme, mainly due to an improvement in the Symptoms score.

\section{Exhaled NO}

Individual and mean values of FeNO measured over time are shown in fig 1 . Despite the wide interpatient variability, mean and individual values of resting FeNO assessed at $\mathrm{T}-1$ and $\mathrm{T} 0$ were very similar (mean (SE) 4.3 (0.6) ppb and $4.4(0.6) \mathrm{ppb}$, respectively; mean (SD) absolute change $0.05(0.15) \mathrm{ppb}(95 \% \mathrm{CI}-0.03$ to $0.14)$ ) and did not differ significantly from those obtained in healthy controls (4.3 $(0.4) \mathrm{ppb})$. In contrast, all but two showed individual increases in FeNO following the pulmonary rehabilitation programme (T1). As a result, a significant mean increase in FeNO was seen following the pulmonary rehabilitation programme to $6.4(0.7) \mathrm{ppb}$ (mean (SD) absolute change 1.97 (2.69) ppb (95\% CI 0.41 to 3.53)).

Figure 2 shows the relationship between changes in exercise tolerance and in FenO before and after the pulmonary rehabilitation programme. A significant correlation $(r=0.60)$ was found.

There was an inverse relationship $(r=-0.71)$ between the increase in FeNO at $\mathrm{T} 1$ and baseline $\mathrm{FEV}_{1}$ (fig 3). No significant relationship was observed between changes in FenO and changes in $6 \mathrm{MWD}$ or SGRQ.

\section{Discussion}

This study is the first to show that, in patients with mild to moderate COPD, improvement in exercise tolerance following a multidisciplinary 


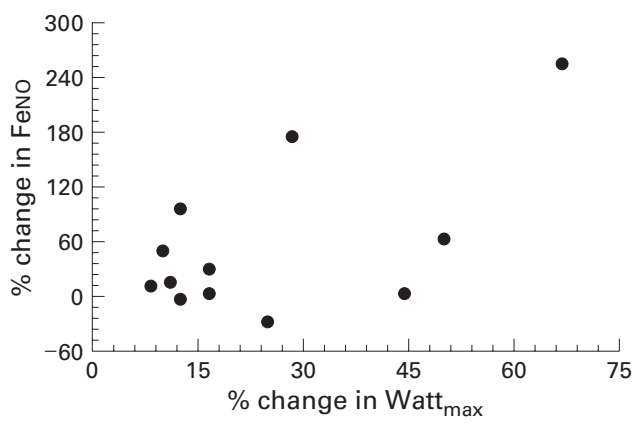

Figure 2 Correlation between changes in FeNO and in maximal work load following pulmonary rehabilitation programme; $r=0.60 ; p<0.05$.

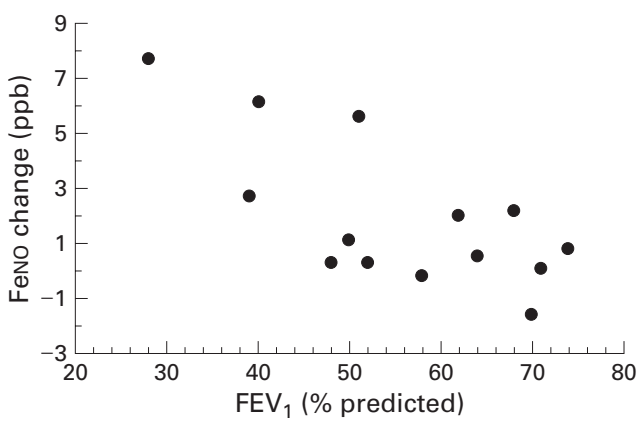

Figure 3 Correlation between change in FeNO elicited by the pulmonary rehabilitation programme and severity of airflow obstruction at admission; $r=-0.71 ; p<0.005$.

pulmonary rehabilitation programme including lower limb training may be associated with an increase in resting eNO.

The baseline mean values of FenO ( $\mathrm{T}-1$ and T0) were lower than those obtained in previous studies in our laboratory in patients with COPD of similar severity. ${ }^{67}$ The discrepancy can be explained by the fact that in this study we used the single breath manoeuvre with a constant expiratory flow of more than $200 \mathrm{ml} / \mathrm{s}$ (range 250-300), whereas in the previous studies a lower expiratory flow was used. Indeed, an inverse relationship between expiratory flow and eNO concentration has been described. ${ }^{26}$ The measurements at $\mathrm{T}-1$ and T0 showed good reproducibility and, as in a previous study, ${ }^{6}$ the mean FenO values observed in our patients with mild to moderate COPD both at $\mathrm{T}-1$ and $\mathrm{T} 0$ did not differ from those recorded in healthy controls.

This study is the first to show an effect of a pulmonary rehabilitation programme on eNO in patients with COPD. Improvement in exercise tolerance was associated with an increase in resting eNO. In a previous study ${ }^{15}$ we observed that eNO increased in patients with mild to moderate COPD during maximal exercise, although to a lower extent than in normal age related sedentary controls. In the previous study most of the increase in eNO was related to the increase in $\dot{\mathrm{V}} \mathrm{E}$. In the present study $\dot{V}_{E}$ at rest did not change over time, therefore we cannot ascribe the changes in eNO following the pulmonary rehabilitation programme to changes in $\dot{\mathrm{V}} \mathrm{E}$.

Compared with untrained normal subjects, studies in athletes reported a greater increase in eNO output during strenuous exercise. ${ }^{14}$ In contrast, other authors have reported that, in normal subjects during exercise, eNO was mainly related to the magnitude of aerobic metabolism and was independent of the level of physical training. ${ }^{27}$ In addition, it has also been shown that resting levels of plasma nitrate (a stable soluble end product of $\mathrm{NO}$ ) are significantly higher in athletes than in sedentary controls and correlate with the peak work rate. ${ }^{28}$ This may suggest an association between physical fitness and formation of $\mathrm{NO}$ with resulting beneficial effects of training on cardiovascular health. ${ }^{28}$

The exercise related increase in eNO in normal subjects has been postulated as deriving mainly from the airway, ${ }^{29}$ perhaps through an upregulation of NO synthase by increased vascular shear stress. Although a vascular origin of eNO has been suggested in acute exercise, ${ }^{30}$ Sartori et $a l^{31}$ have recently demonstrated in healthy humans that pulmonary eNO is mostly of epithelial rather than endothelial origin, and does not provide a marker for vascular or endothelial function.

This study has shown a significant correlation between changes in eNO and in peak work load following a pulmonary rehabilitation programme in patients with stable COPD. An increase in eNO was recorded after the pulmonary rehabilitation programme in almost all the patients studied (12 out of 14). The two patients whose NO value decreased or remained unchanged were unable to reach the optimal plateau according to the exercise training protocol adopted (see Methods), starting below $50 \%$ of the initial work load because of severe dyspnoea. Interestingly, the change in eNO in our COPD patients after the pulmonary rehabilitation programme was inversely related to the degree of baseline airway obstruction (fig 3). Only the most severe COPD patients (ATS disease stage III) and those with an associated cor pulmonale are known to produce lower levels of eNO, ${ }^{67}$ probably due to reduced expression and activity of constitutive NO synthase. Since the patients in the study were in ATS disease stages I or II, we did expect similar production of NO from the airway both at rest and during effort. Nevertheless, suggested positive effects on vasodilation, ${ }^{32}$ bronchodilation, ${ }^{33} 34$ and ventilation-perfusion distribution ${ }^{35}$ resulting from enhanced NO activity might have favoured the most obstructed patients in the study.

In contrast with the incremental cycloergometer exercise test, no significant relationship was observed between changes in FeNO and in 6MWD after the pulmonary rehabilitation programme. This may reflect differences between modalities of the exercise test, the 6MWD reflecting endurance capacity more than the incremental test. ${ }^{36}$ The lack of a relationship between changes in eNO and in HRQL is not surprising and probably reflects the comprehensive nature of the pulmonary rehabilitation programme and the fact that HRQL depends on more than just exercise ability. ${ }^{17}$ 
The most important limitation of this study is the lack of a randomised protocol with a control group. However, due to the prospective design and the lack of change in eNO during the run in period, we are confident that the pulmonary rehabilitation programme was the major determinant for the observed changes in eNO. Indeed, both eNO and exercise tolerance increased after the pulmonary rehabilitation programme, but not during the run in period, with at least $36 \%$ of the change in eNO being accounted for by the increase in exercise tolerance (fig 2).

In conclusion, with the limitation of the lack of a randomised control population, our study suggests that an increase in exercise tolerance related to a pulmonary rehabilitation programme may be associated with an increase in eNO in patients with mild to moderate COPD. eNO might, at least theoretically, be a useful marker for assessing the pathophysiological adaptation to training in patients with COPD. Further prospective randomised controlled studies are needed to better define this role.

1 Bernareggi M, Cremona G. Measurement of exhaled nitric oxide in humans and animals. Pulmon Pharmacol Ther 1999;12:331-52.

2 Kharitonov SA, Yates D, Robbins RA, et al. Increased nitric oxide in exhaled air of asthmatic patients. Lancet 1994;343. 133-5.

3 Kharitonov SA, Wells AU, O'Conner BJ, et al. Elevated levels of exhaled nitric oxide in bronchiectasis. Am $\mathcal{f}$ Respir els of exhaled nitric oxide in bro
Crit Care Med 1995;151:1889-93.

4 Rolla G, Colagrande P, Brussino L, et al. Exhaled nitric oxide and pulmonary response to iloprost in systemic sclerosis with pulmonary hypertension. Lancet 1998;351:14912.

5 Sumino H, Sato K, Sakamaki T, et al. Decreased basal production of nitric oxide in patients with heart disease. Chest 1998;113:17-22.

6 Clini E, Bianchi L, Pagani M, et al. Endogenous nitric oxide in stable COPD patients: correlates with severity of disease. Thorax 1998;53:881-3.

7 Clini E, Cremona G, Campana M, et al. Production of nitric oxide in COPD patients with cor pulmonale: correlates with echo-doppler assessment Am f Respir Crit Care Med 2000;162:446-50

8 American Thoracic Society. Standards for the diagnosis and care of patients with chronic obstructive pulmonary
disease. Am 7 Respir Crit Care Med 1995;152:S77-120.

9 Maziak W, Loukides S, Culpitt S, et al. Exhaled nitric oxide in chronic obstructive pulmonary disease. Am f Respir Crit in chronic obstructive pulmona
Care Med 1998;157:998-1002.

10 Agustì AGN, Villaverde JM, Togores B, et al. Serial measurements of exhaled nitric oxide during exacerbations of chronic obstructive pulmonary disease. Eur Respir $\mathcal{F}$ 1999;14:523-8

11 Gosselink R, Decramer M. Muscle training in pulmonary rehabilitation. Eur Respir Mon 2000;13:99-110.

12 ACCP/AACVPR. Pulmonary rehabilitation. Joint ACCP AACVPR evidence-based guidelines. Chest 1997;112 1363-96.

13 Persson MG, Wiklund NP, Gustafsson LE. Endogenous nitric oxide in single exhalations and the change during exercise. Am Rev Respir Dis 1993;148:1210-14.
14 Maroun MJ, Metha S, Turcotte R, et al. Effects of physical conditioning on endogenous nitric oxide output during exercise. F Appl Physiol 1995;79:1219-25.

15 Clini E, Bianchi L, Vitacca M, et al. Exhaled nitric oxide (eNO) and exercise in stable COPD patients. Chest 2000;117:702-5.

16 Lacasse Y, Wong E, Guyatt GH, et al. Meta-analysis of respiratory rehabilitation in chronic obstructive pulmonary disease. Lancet 1996;348:1115-9.

17 Foglio K, Bianchi L, Bruletti G, et al. Long-term effectiveness of pulmonary rehabilitation in patients with chronic airway obstruction. Eur Respir f 1999;13:125-32.

18 Quanjer PH. Working Party on Standardization of Lung Function Tests. Bull Eur Physiopathol Respir 1983;19(Suppl 5):7-10.

19 Beaver WL, Wasserman K, Whipp BJ. A new method for detecting the anaerobic threshold by gas exchange. $\mathrm{f} A p p l$ Physiol 1986;60:2020-7.

20 Borg GAV. Psychophysical basis of perceived exertion. Med Sci Sports Exerc 1992;14:377-81.

21 Butland RJA, Pang J, Gross ER, et al. Two, six and 12 minute walking tests in respiratory disease. BMF 1982;284: 1607-8.

22 Jones PW, Quirk FH, Baveystock CM, et al. A self-complete measure of health status for chronic airflow limitation. Am Rev Respir Dis 1992;145:1321-7.

23 Simpson A, Custovic A, Pipis S, et al. Exhaled nitric oxide, sensitization, and exposure to allergens in patients with asthma who are not taking inhaled steroids. Am $\mathcal{F}$ Respir Crit Care Med 1999;160:45-9.

24 Maltais F, LeBlanc P, Jobin J, et al. Intensity of training and physiologic adaptation in patients with chronic obstructive pulmonary disease. Am F Respir Crit Care Med 1997;155: 555-61.

25 Clark CJ, Cochrane L, Mackay E. Low intensity peripheral muscle conditioning improves exercise tolerance and breathlessness in COPD. Eur Respir 7 1996;9:2590-6.

26 Silkoff PE, McClean PA, Slutsky AS, et al. Marked flow-dependence of exhaled nitric oxide using a new technique to exclude nasal nitric oxide. Am f Respir Crit Care Med 1997;155:260-7.

27 Chirpaz-Oddou MF, Favre-Juvin A, Flore P, et al. Nitric oxide response in exhaled air during an incremental exhaustive exercise. 7 Appl Physiol 1997;82:1311-8.

28 Jungersten L, Ambring A, Wall B, et al. Both physical fitness and acute exercise regulate nitric oxide formation in healthy humans. $\mathcal{F}$ Appl Physiol 1997;82:760-4.

29 Phillips CR, Giraud GD, Holden W. Exhaled nitric oxide during exercise: site of release and modulation by ventilation and blood flow. F Appl Physiol 1996;80:186571.

30 Bauer JA, Wald JA, Doran S, et al. Endogenous nitric oxide in expired air: effects of acute exercise in humans. Life Sci 1994;55:1903-9.

31 Sartori C, Lepori M, Busch T, et al. Exhaled nitric oxide does not provide a marker of vascular endothelial function in healthy humans. Am $\mathcal{F}$ Respir Crit Care Med 1999;160: 879-82

32 Dupuy PM, Shore SA, Drazen JM, et al. Bronchodilator action of nitric oxide in guinea pigs. $\mathcal{F}$ Clin Invest 1992;90: 421-8.

33 Ricciardolo FLM, Di Maria GU, Mistretta A, et al. Impairment of bronchoprotection by nitric oxide in severe asthma. Lancet 1997;350:1298

34 McAllister RM, Hirai T, Musch TI. Contribution of endothelium-derived nitric oxide (EDNO) to the skeletal muscle blood flow response to exercise. Med Sci Sports Exerc 1995;27:1145-51.

35 Moncada S, Higgs A. The L-arginine nitric oxide pathway. $N$ Engl f Med 1993;329:2002-12.

36 Sergysels R, Killian K, Roca J. Exercise testing in the assessment of impairment/disability. In: Roca J, Whipp BJ, eds. Clinical exercise testing. Eur Respir Mon 1997;2:115-28. 